\title{
The Recent Decline of the Arctic Summer Sea-Ice Cover in the Context of Internal Climate Variability
}

\author{
W. Dorn ${ }^{*}, 1$, K. Dethloff ${ }^{1}$, A. Rinke ${ }^{1}$ and M. Kurgansky ${ }^{2,3}$ \\ ${ }^{1}$ Alfred Wegener Institute for Polar and Marine Research, Potsdam, Germany \\ ${ }^{2}$ Department of Geophysics, University of Concepción, Concepción, Chile \\ ${ }^{3}$ A.M. Obukhov Institute of Atmospheric Physics, Moscow, Russia
}

\begin{abstract}
By means of a 21-year simulation of a coupled regional pan-Arctic atmosphere-ocean-ice model for the 1980s and 1990s and comparison of the model results with SSM/I satellite-derived sea-ice concentrations, the patterns of maximum amplitude of interannual variability of the Arctic summer sea-ice cover are revealed. They are shown to concentrate beyond an area enclosed by an isopleth of barotropic planetary potential vorticity that marks the edge of the cyclonic rim current around the deep inner Arctic basin. It is argued that the propagation of the interannual variability signal farther into the inner Arctic basin is hindered by the dynamic isolation of upper Arctic Ocean and the high summer cloudiness usually appearing in the central Arctic. The thinning of the Arctic sea-ice cover in recent years is likely to be jointly responsible for its exceptionally strong decrease in summer 2007 when sea-ice decline was favored by anomalously high atmospheric pressure over the western Arctic Ocean, which can be regarded as a typical feature for years with low sea-ice extent. In addition, unusually low cloud cover appeared in summer 2007, which led to substantial warming of the upper ocean. It is hypothesized that the coincidence of several favorable factors for low sea-ice extent is responsible for this extreme event. Owing to the important role of internal climate variability in the recent decline of sea ice, a temporal return to previous conditions or stabilization at the current level can not be excluded just as further decline.
\end{abstract}

\section{INTRODUCTION}

The possible disappearance of the Arctic summer sea-ice cover and its time are currently discussed among climate researchers in view of the rapid decrease of summer sea ice in recent years $[1,2]$. Since the observed downward trend is much greater than in most simulations of the climate models participating in the Intergovernmental Panel on Climate Change Fourth Assessment Report (IPCC AR4) [3], it is often argued that the Arctic Ocean will possibly become ice free during summer already within the next few decades. At least the fact that all IPCC AR4 climate models show longterm decline of Arctic sea ice from the 1990s onwards [3] indicates that greenhouse gases are an important factor for ongoing changes in the Arctic climate system. The record low of the Arctic sea-ice cover in summer 2007 [4] additionally supports the assumption that the downward trend in Arctic summer sea-ice cover is an evidence for human-induced climate change and will not reverse in the near future.

Even though it is increasingly difficult to argue against the more accepted view that the recent changes in the Arctic represent a fingerprint of ongoing global warming, it is very unlikely that the decline in sea ice is solely caused by higher temperatures. Despite clear evidence that the Arctic has warmed in recent years [5], which implies reduced ice

*Address correspondence to this author at the Alfred Wegener Institute for Polar and Marine Research, Telegrafenberg A43, D-14473 Potsdam, Germany; Tel: +49-331-288-2164; Fax: +49-331-288-2178;

E-mail: Wolfgang.Dorn@awi.de growth in winter, a longer melt season [6], and enhanced ice melt in summer, there is also some evidence that internal climate variability plays a key role in terms of the recent changes $[1,7]$. Though, it could be possible that respective changes in the frequency or amplitude of dominant atmospheric variability modes have been triggered by anthropogenic warming as supposed by Corti et al. (1999) [8].

However, climate model results differ widely in their response to global change and have to be interpreted with care, in particular with respect to the simulation of Arctic sea ice [9]. Furthermore, the mechanisms of internal climate variability are not well enough understood to exclude natural causes for the exceptionally strong decline of the Arctic summer sea-ice cover during the last years. While the main causes of the interannual variability of the Arctic sea-ice cover are likely to be attributed to year-to-year variations in the atmospheric fields of wind and temperature $[10,11]$, it remains more uncertain what is the maximum possible amplitude of these variations with respect to the summertime Arctic sea-ice cover spread. The answer on the last question might give a certain clue for setting definite limits for the Arctic sea-ice cover retreat in terms of natural variability.

Paleoclimatic proxy data and model results, representing exceptionally warm epochs, especially at $6 \mathrm{kyr}$ BP [12], indicate that the Arctic sea-ice cover may survive also in a warmer climate and could have a minimal size determined for instance by the oceanic circulation and the thermal regime of seawater beneath a permanent ice pack. During the major climate warming at $6 \mathrm{kyr} \mathrm{BP}$, when air temperatures in 
the Arctic were 2-4 $\mathrm{K}$ higher than today, the perennial sea ice did not completely disappear but was only reduced by about $25 \%$. However, since the mid-Holocene warming differs from the present warming (increased solar forcing during the boreal summer versus increasing greenhouse gas forcing throughout the year), the total disappearance of Arctic summer sea ice can not be excluded as a possible feature of the Arctic climate system's trajectory.

An ice free Arctic Ocean would definitely have broad implications for Arctic ecosystems, indigenous people, transportation, etc., but also significant feedbacks on the global atmospheric and oceanic circulations are very likely $[13,14]$ and indicate the prime importance of knowing the fate of the Arctic sea-ice cover. However, it is still unclear whether the decrease of summer sea ice will continue at the same or even higher rate, or whether there are some physical factors which could counteract this process.

In this article, the interannual variability of the Arctic summer sea-ice cover is analyzed by means of a multi-yearlong simulation of a coupled regional pan-Arctic atmosphere-ocean-ice model for the 1980s and 1990s and comparison of the model results with SSM/I satellite-derived sea-ice concentrations. The typical atmospheric circulation patterns in "high-ice" and "low-ice" phases are compared and semi-quantitative arguments for a potential limitation of the area of summer sea-ice variability are discussed and linked to recent changes in summer sea-ice cover.

\section{VARIABILITY OF THE SUMMER SEA-ICE COVER}

\section{Interannual Variability}

To analyze the status quo of interannual variability of the Arctic summer sea-ice cover, a 21 year-long simulation of the coupled regional pan-Arctic atmosphere-ocean-ice model HIRHAM-NAOSIM [15] was used. The model was driven at the lateral boundaries of the atmosphere component and the surface boundaries outside the overlap area of the two model domains using the most recent European Centre for MediumRange Weather Forecasts reanalysis data (ERA-40). All other external climate forcing factors were taken as fixed constants or from climatology. For more details, it is referred to the paper of Dorn at al. (2007) [15].

The coupled model simulation started in 1980, the first 8 years were regarded as model spin-up time, as recommended by Dorn et al. (2007) [15], and the last 13 years (1988-2000) were analyzed. Fig. (1) shows the time series of the simulated Arctic sea-ice extent and sea-ice volume in September, the former in comparison with SSM/I satellite-derived data [16]. The simulated data show temporal correspondence with the observations, indicating the impact of the large-scale atmospheric circulation on the sea-ice simulation, except for the years 1992-1994. This discrepancy could be related to the Mount Pinatubo eruption in 1991, a major external forcing event whose climatic effect (cf. Robock, 2003, and references therein) [17] was accounted in the model simulation only indirectly, via the lateral boundary forcing by ERA-40
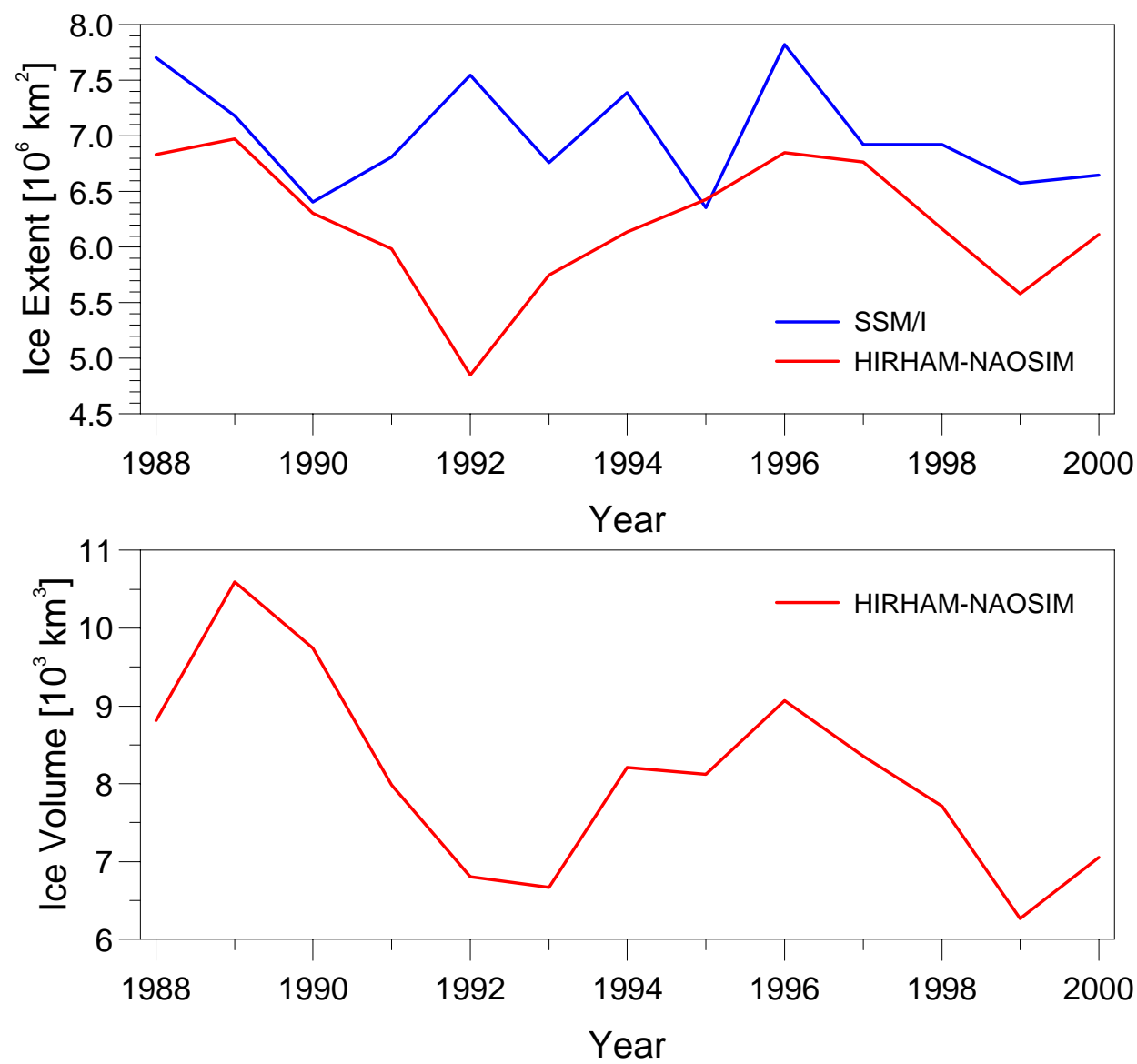

Fig. (1). Arctic sea-ice extent and volume in September from 1988 to 2000. The blue line depicts SSM/I satellite-derived data and the red lines on both panels show simulation results of HIRHAM-NAOSIM. 
data. Therefore, the comparison between the red and the blue line on the upper panel in Fig. (1) might give a rough estimate of the cooling effect of the Pinatubo eruption-caused aerosol over the Arctic onto the summertime climate conditions.

Within the 13-year period, the modeled sea-ice volume in September decreases by about $2000 \mathrm{~km}^{3}$, though not continuously but superposed by a quasi-decadal oscillation $[18,19]$, which positive and negative phases approximately correspond to the maxima and minima in sea-ice extent. These discontinuous trends in sea-ice extent and volume are likely to relate to variations in the poleward heat transport due to altered atmospheric circulation patterns [7,20,21], specified by the model's boundary forcing with ERA-40 data. Also, the general loss of ice within this period can only be a consequence of changes in the large-scale atmospheric circulation, since all other external model forcing agents were kept constant at run time (in particular no increase in greenhouse gases).

The strongest reduction in ice volume appears between 1990 and 1991, reflecting a massive loss of thick multi-year ice also found in observational data [22]. However, the longterm loss of ice volume within the period from 1988 to 2000
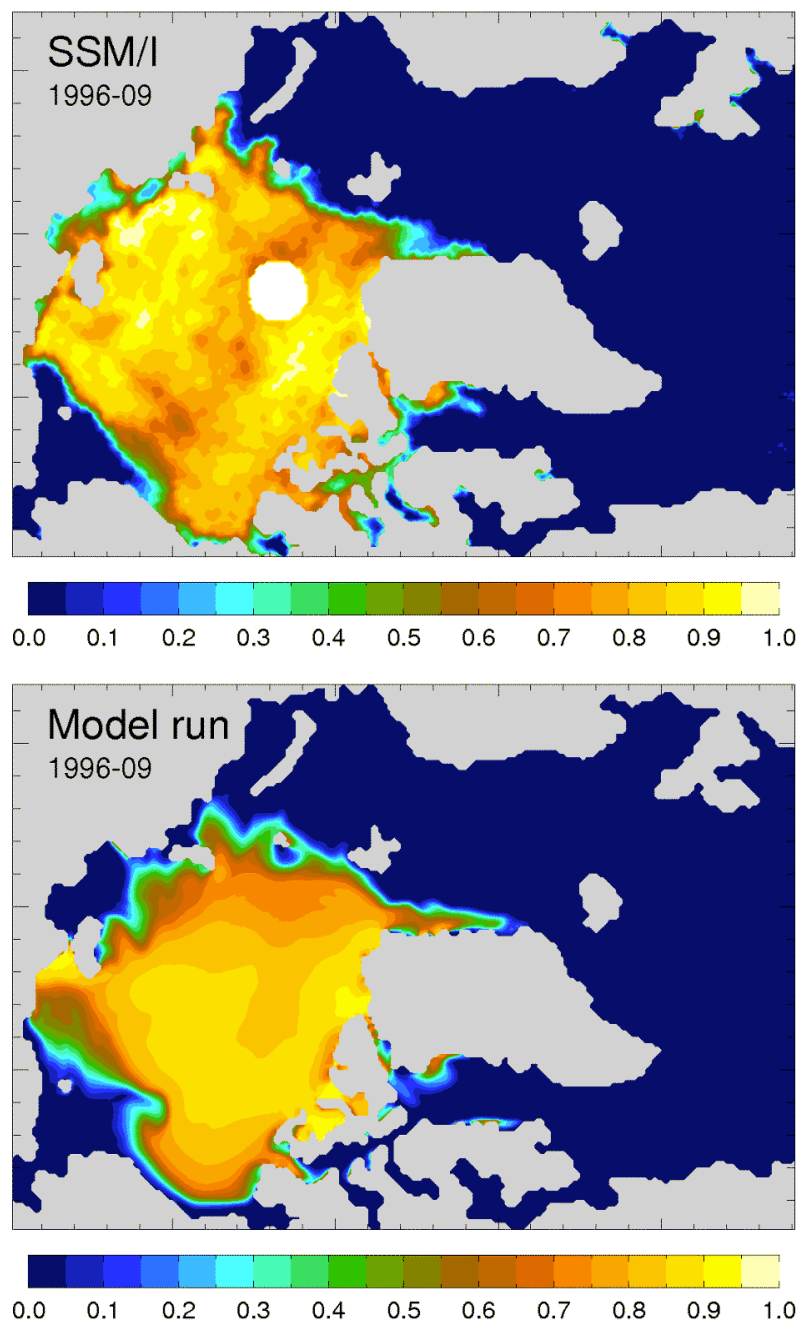

does not represent a sufficient condition for a comparable reduction in the summer minimum in ice extent, in spite of the concurrence of high-ice and low-ice years in ice extent and ice volume. Long-term trends in observed and modeled summer ice extent are found to be rather small and insignificant. This leads to the conclusion that thinning of the ice pack not necessarily results in strong decline of the summer sea-ice cover, but only increases its sensitivity to variations in the atmospheric and oceanic circulations.

\section{Spatial Variability}

To demonstrate regional differences between high-ice and low-ice phases, two years, 1996 and 1999, have been selected as an example of years in which the September seaice extent was either high (1996) or low (1999) in both the model and satellite data (see Fig. 2). The model simulations capture fairly well not only the lateral extension of the Arctic ice cover but also some details of the position of its edge. The largest deviations from the observations appear in the Laptev and Kara seas and with respect to the open water fraction within the ice pack.

Despite some agreement between model simulation and satellite data, years with high and low September sea-ice
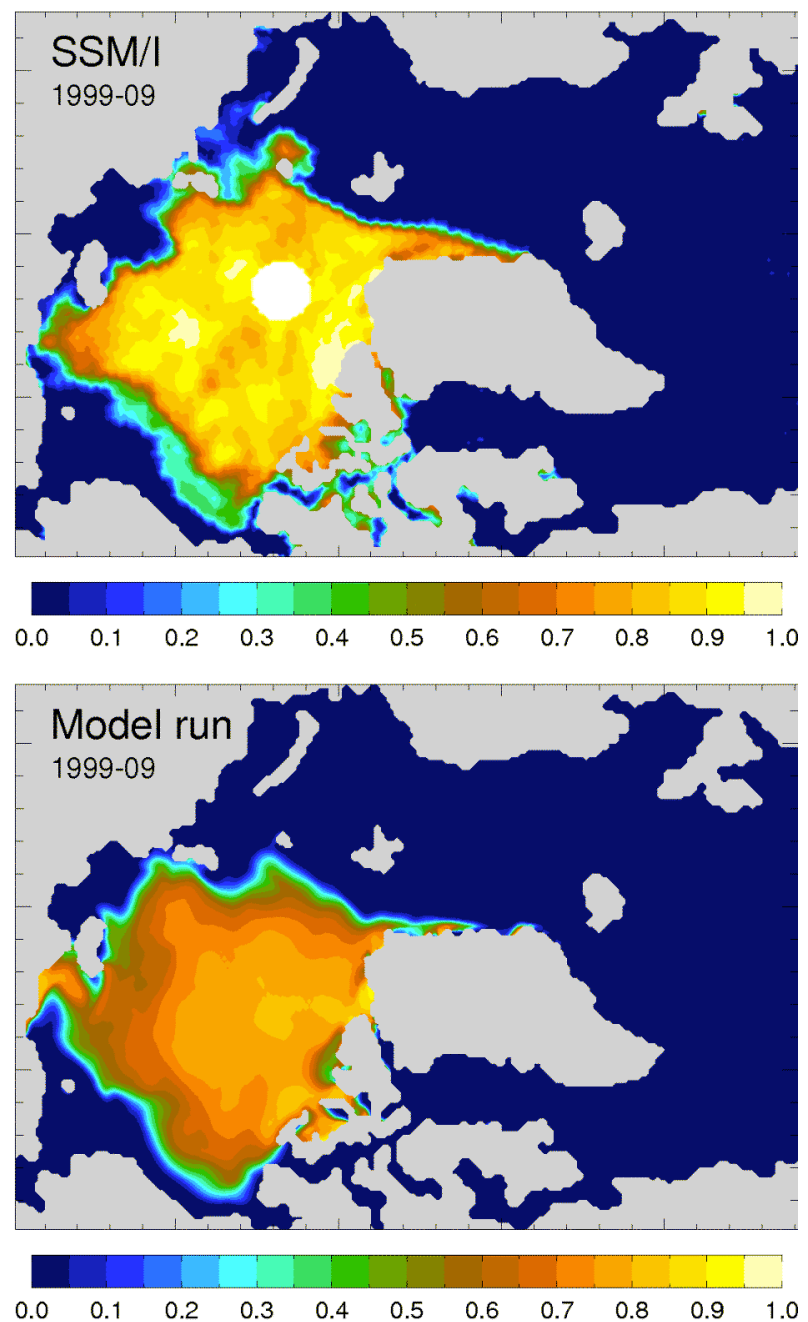

Fig. (2). Observed (top) and simulated (bottom) sea-ice concentration in September for two selected years with "high-ice" (1996; left) and "low-ice" conditions (1999; right). 
extent, respectively, are not always equal in both data sets. Therefore composites of high-ice and low-ice phases have been compiled independently from each other. In each case the four years with highest and lowest sea-ice extent have been chosen as high-ice and low-ice years respectively. High-ice years are, in descending order, 1996, 1988, 1992, and 1994 in the satellite data and 1989, 1996, 1988, and 1997 in the model simulation, while low-ice years are 1995, 1990, 1999, and 2000 in the satellite data and 1992, 1999, 1993, and 1991 in the model simulation (see Fig. 1). Fig. (3) shows the differences between the two composites (top panel) as well as the standard deviations of September seaice concentration within the period 1988-2000 (bottom panel). Both the difference and standard deviation patterns give a portrait of the spatial distribution of the amplitude of interannual variability in September sea-ice cover and clearly show that virtually all the variability maxima were concentrated over the Arctic shelf zone, while variability over the deep Arctic Ocean basin occurred only marginally. This means that at least from the perspective of the late 1980s and the 1990s, there is a minimum summertime Arctic sea-ice area, not involved in interannual variability. This area appears stricter in the observations than in the model simulation, where the variability enters deeper into the central Arctic.

\section{Recent Changes}

Almost every year since 2001 has shown pronounced September minima, the most extreme of which were in 2005 and 2007. When compared with the mean September sea-ice extent over the period 1979 to 2000 , these minima represent a spatial reduction of $21 \%$ in 2005 [2] and even almost $40 \%$ in 2007 [4]. Still, even in September 2005, the sea-ice cover spreads beyond the deep Arctic Ocean basin, marked conventionally by a $2000 \mathrm{~m}$ isobath. In contrast, the year 2007 was really anomalous [4], as it was the first time within the observational record when the sea-ice retreat entered the Arctic basin.

The question arises whether the exceptional record low in 2007 already reveals irreversible global changes or can just be regarded as an extreme manifestation of natural climate variability. Given the statistically short time series of available data, this question can not be answered definitely, since a single extreme event can either represent a signal or just be an outlier. Instead, some semi-quantitative arguments are here discussed, which could provide a better insight into the processes which might be responsible for a suppressed propagation of the variability signal into the inner Arctic.

\section{POTENTIAL LIMITATIONS OF THE VARIABILITY}

\section{Dynamic Arguments}

As a result of the potential vorticity (PV) conservation law, the oceanic circulation within the deep Arctic basin tends to be dynamically isolated from much shallower circulations over the Arctic shelves by a barrier of steep PV gradients, which greatly reduces the lateral exchange of water mass and, hence, the export of warmer waters into the inner Arctic basin. It resembles the polar vortex in the winter stratosphere, whose sharp PV edge serves as an eddy meridi- onal transport barrier and explains the existence of the Antarctic ozone hole [23]. Also, a summertime ice drift, consistent with the seawater circulation beneath, can impose a negative feedback on the ice melting process by laterally compressing and ridging the ice and thus preventing its thinning [12].

Available observational oceanographic data indicate a basin-wide cyclonic rim in the mid-depth range, beneath the very shallow Arctic thermocline and halocline [24,25]. In this geostrophically-balanced nearly barotropic motion, the Arctic water-masses closely follow the isobaths $H=$ const by approximately conserving the planetary potential vorticity $q=f / H$, equal to the nearly uniform planetary vorticity $f \cong 1,46 \times 10^{-4} \mathrm{~s}^{-1}$ divided by the oceanic total depth $H$. Despite this observation-based picture is conceptually so transparent, especially from the PV-conservation perspective, the Arctic Ocean Model Intercomparison Project (AOMIP) models encountered difficulties in reproducing the right sense of this circulation, since several AOMIP models produced cyclonic circulations and the remaining models generated anticyclonic ones $[24,26]$. In particular, in a version of the regional NAOSIM model, the flow stays cyclonic during the 1980s and 1990s [24]. Anyway, based on both the observations and the PV-conservation law, one might expect some manifestation of a summertime joint ocean-sea ice circulation inside a closed domain $\Omega$ encircled by a bundle of isopleths $q=$ const, corresponding to a stripe of the steepest PV gradients, $|\nabla q|=\max$, thus marking the transition from the shelf zone to the deep inner ocean basin. Isopleths of PV in the Arctic Ocean are shown in Fig. (4) and demonstrate a parallelism between the bundle of PVcontours computed for $H=500-2000 \mathrm{~m}$ and the outer edge of the domain with nearly vanishing signal in Fig. (3).

\section{Thermodynamic Arguments}

The temperature of very cold Arctic seawater in a thin ice-adjacent layer only slightly exceeds the freezing temperature of seawater. Owing to the well-pronounced shallow Arctic halocline, it makes the oceanic stratification hydrostatically very stable in presence of the warmer and more saline Atlantic Water at greater depths. This 'thermoinsulating film', or 'blanket', beneath the ice pack explains a generally small annual-mean ocean-to-ice upward heat flux. Due to this insulating effect of the upper waters from the oceanic waters at greater depth, an inflow of warm and salty intermediate Atlantic waters into the Arctic basin as observed during the last years $[27,28]$ might exert influence on ice melting only at longer time scales as long as the Arctic halocline persists. Changes in the persistence of the cold halocline layer have already been observed [29], but these changes do not necessarily be persistent themselves [30]. The future behavior of the Arctic halocline can hardly be estimated and remains a 'key wild card' [2].

On the other hand, the shallow upper layer in the Arctic Ocean can easier be warmed up by atmospheric energy input, especially by penetrating solar radiation (see Maykut and Perovich, 1987) [31]. Even if the inner Arctic represents 

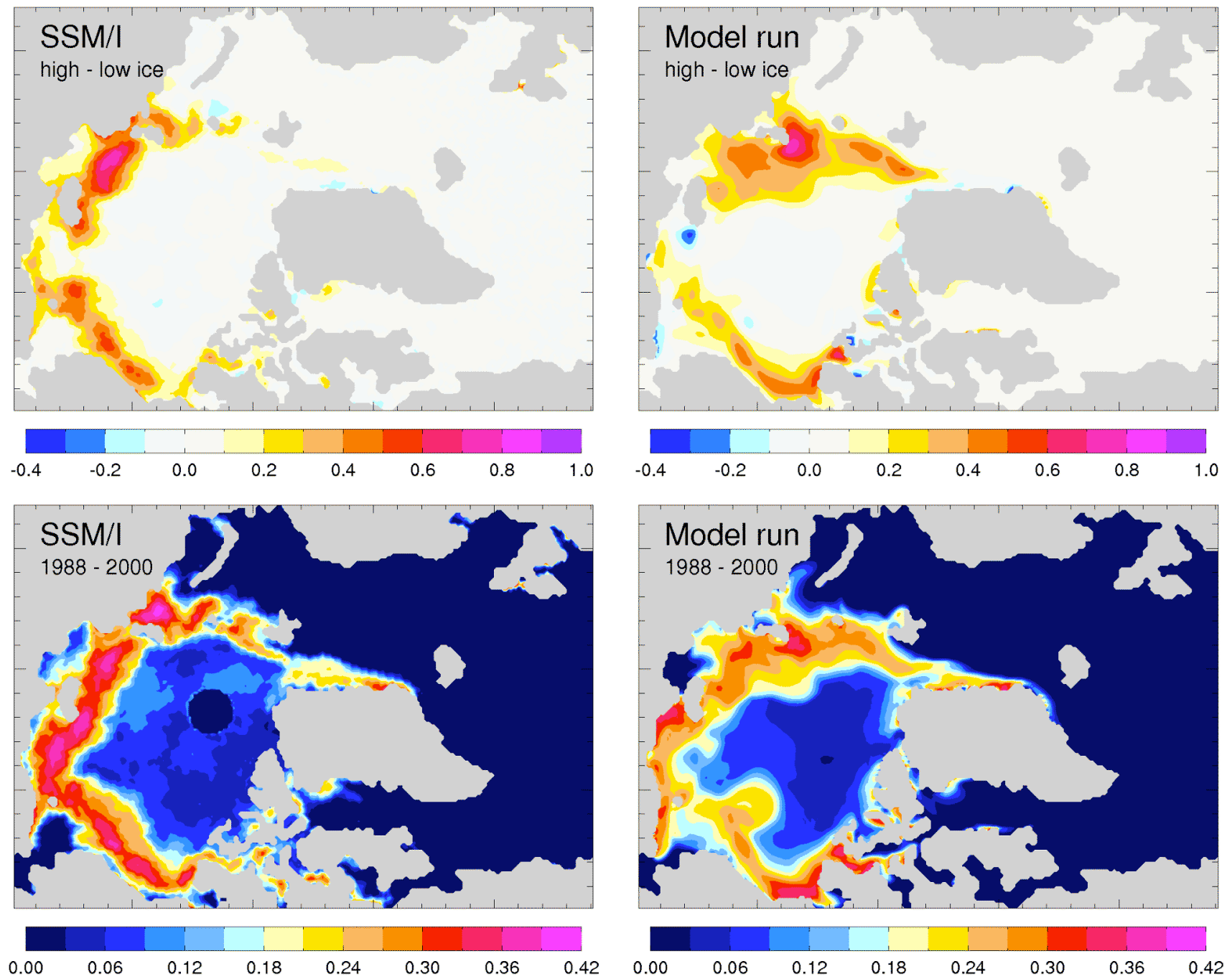

Fig. (3). Observed (left) and simulated (right) differences in September sea-ice concentration between selected "high-ice" and "low-ice" years (top panel) and standard deviations of September sea-ice concentration within the period 1988-2000 (bottom panel). High-ice years are 1996, 1988, 1992, and 1994 in the observation and 1989, 1996, 1988, and 1997 in the model simulation, while low-ice years are 1995, 1990, 1999, and 2000 in the observation and 1992, 1999, 1993, and 1991 in the model simulation.

the northernmost part of the globe, the diurnally averaged insolation at the top of the atmosphere has its global maximum just over the polar regions during the polar day. However, the amount of solar radiation, incident on the Earth's surface in the inner Arctic, is largely affected by the presence of clouds during the short summer period. In particular in summer, the inner Arctic is characterized by a cloud cover fraction of about $80 \%$ on average $[32,33]$ that reduces the amount of heat energy available for thermodynamic loss of ice.

Fig. (5) shows the mean cloud cover fraction during summer (June to September) within the period 1988-2000 from ERA-40 data and the coupled model simulation. Despite quantitative differences, both data sets show similar patterns and demonstrate that just over the central Arctic Ocean the highest cloud cover fraction occurs. The resulting lower solar radiation at the surface gives rise to conclude that the inner Arctic can easier hold perennial ice which survives the melting period. Perennial ice, in turn, is less vulnerable

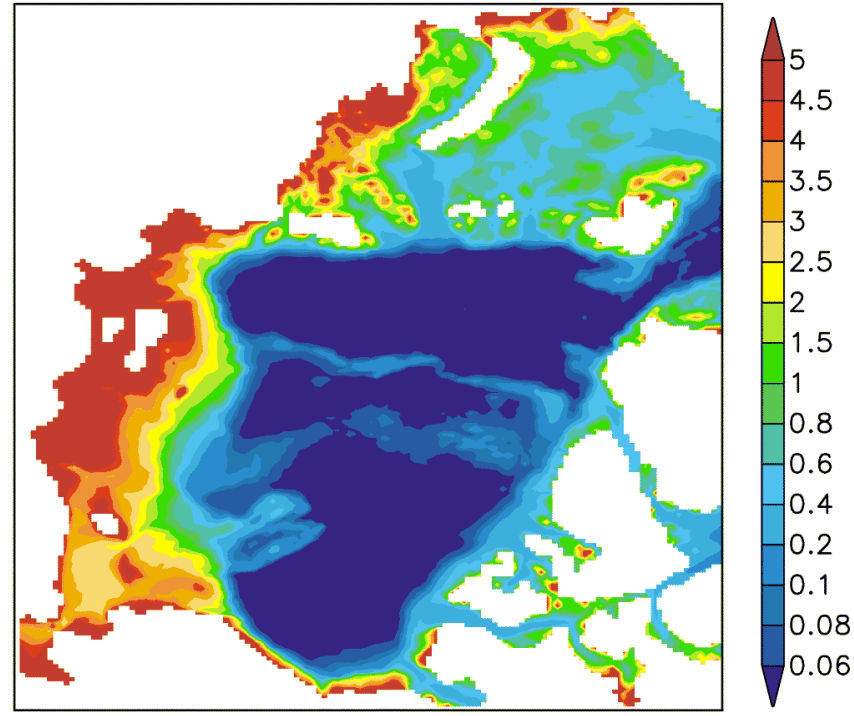

Fig. (4). Isopleths of the planetary PV (in units $10^{-6} \mathrm{~m}^{-1} \mathrm{~s}^{-1}$ ) in the Arctic Ocean (see also the text). 

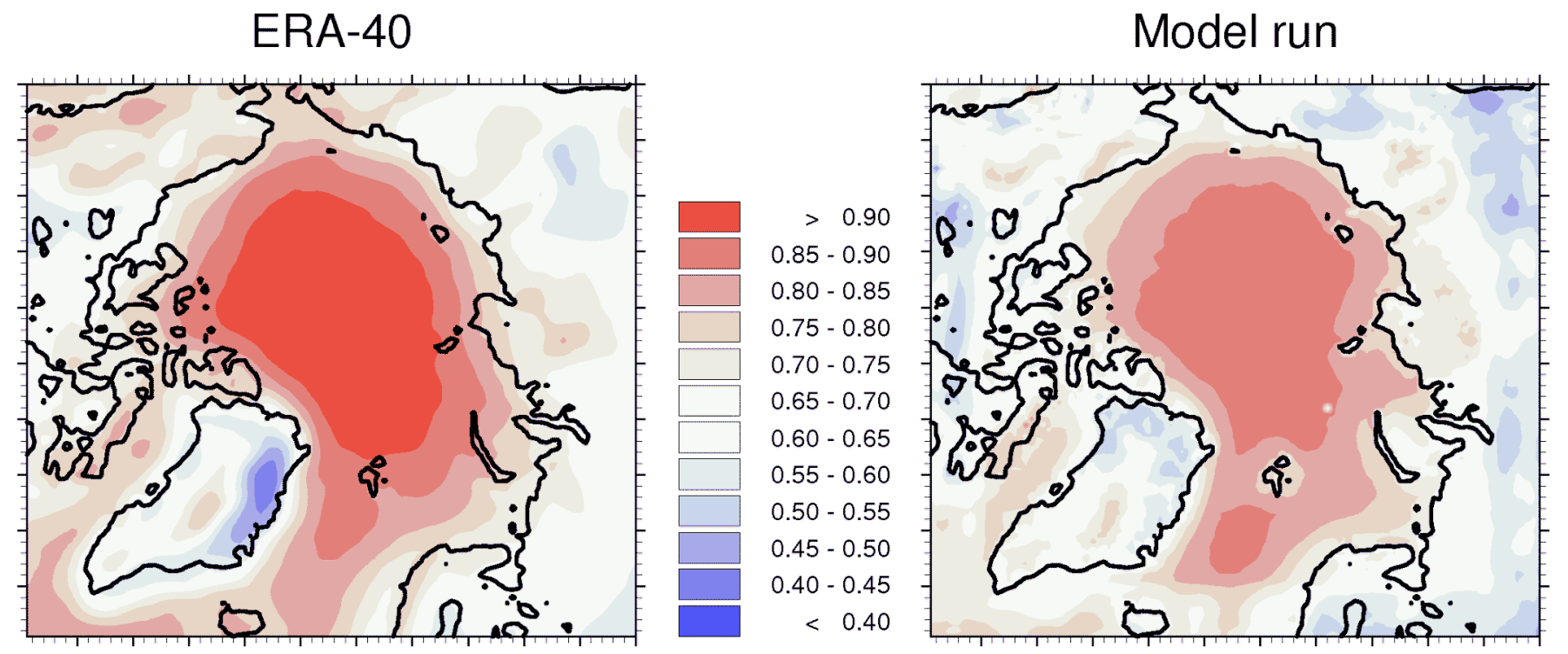

Fig. (5). Mean cloud cover fraction during summer (June to September) within the period 1988-2000 from ERA-40 data (left) and the coupled model simulation (right).

to thermal forcing than seasonal ice [1] so that the inner Arctic area of perennial ice might represent a metastable state, at least from a thermodynamical point of view.

\section{ASSOCIATED VARIATIONS OF THE ATMO- SPHERIC CIRCULATION}

Sea ice may be regarded as an integrator of oceanic and atmospheric changes. As briefly outlined at the beginning, sea-ice variability is likely to be triggered by variations in the atmospheric circulation. It was concluded in the past that reductions in sea-ice extent are associated with positive phases of the Arctic Oscillation (AO), since there was a parallelism between high AO index and low sea-ice extent from the late 1980s through the mid-1990s [34,7]. Since the mid1990s however, this coexistence has not appeared anymore. Maslanik et al. (2007) [7] have argued that the mismatch between the AO index and loss of sea-ice can be explained by the frequency of occurrence of three main sea level pressure patterns which were in phase until the mid-1990s and have varied differently since then.

Fig. (6) shows the mean sea level pressure patterns in summer (June to September) in high-ice and low-ice years as well as the difference between both composites, each from ERA-40 data and the model simulation. The composites of high-ice and low-ice years are exactly the same as in Fig. (3), except that ERA-40 data here represent the observations. As a common feature, summers with high sea-ice extent show low pressure over the central Arctic, while summers with low sea-ice extent are characterized by an Arctic highpressure area with its center over the Beaufort Sea. This feature is in agreement with findings by Ogi and Wallace (2007) [11] who analyzed atmospheric and sea-ice data for the period 1979-2006. They hypothesized that the summer circulation affects sea ice principally by means of the Ekman drift in the marginal seas.

Although the composites of high-ice and low-ice years from ERA-40 and model data do not comprise the same years, the difference patterns are quite similar, indicating the prime importance of the atmospheric circulation for generating interannual variability in summer sea ice. The differences show an AO-like pattern during summer, which resembles the positive phase of the $\mathrm{AO}$, when relatively low pressure occurs in the central Arctic. Rigor and Wallace (2004) [22] argued that negative phase of the summer AO favors a decrease in sea-ice concentrations due to an increase in the advection of warm air onto the ice and the advection of ice away from the coast (offshore Ekman drift in consequence of easterly winds along the coast). Both processes accelerate sea-ice retreat in the shelf regions of the Arctic Ocean.

It should be noted that the differences in mean sea level pressure are, even though well pronounced, statistically not significant. The atmospheric circulation varies considerably from summer to summer and also during each summer season, clearly indicating that not only one pattern involves high or low sea-ice extent, but a variety of different circulation patterns is accompanied by regionally different sea-ice retreat. Hence, low ice extent may also occur in case of low pressure over the Arctic Ocean as in 2002 [35], possibly when for instance anomalously warm southerly winds in spring contribute to early opening of the offshore ice cover.

The strong influence of the summertime atmospheric circulation on the sea-ice drift is demonstrated in Fig. (7) by means of the difference vectors of the simulated mean ice drift velocities in high-ice and low-ice years. During high-ice years, the ice motion is (in qualitative agreement with lower sea level pressure) more cyclonic than in low-ice years, the transpolar drift is less pronounced, and the outflow of sea-ice through Fram Strait is weaker. In addition, ice drift toward the Laptev and northern Kara seas, where the differences in ice concentration are particularly high (see Fig. 3), is a feature of most high-ice years. In agreement with the concept of two regimes of wind-driven circulation in the Arctic Ocean [36], the model simulations show predominantly cyclonic ice-drift patterns in high-ice years and anticyclonic patterns in low-ice years. 
ERA-40, high-ice

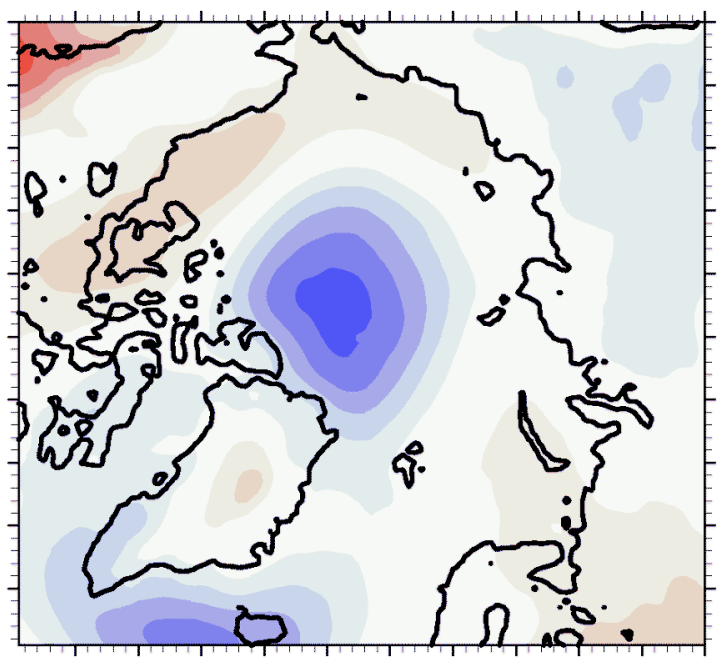

ERA-40, low-ice

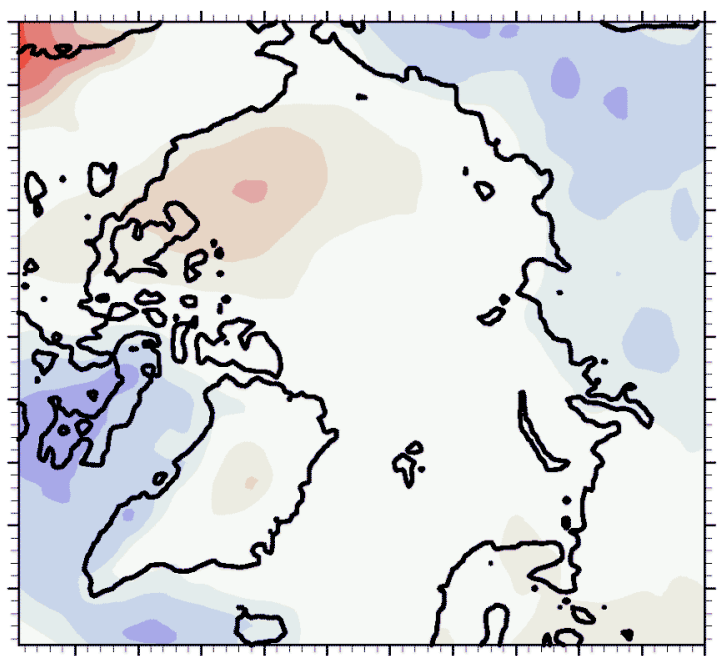

ERA-40, high - low

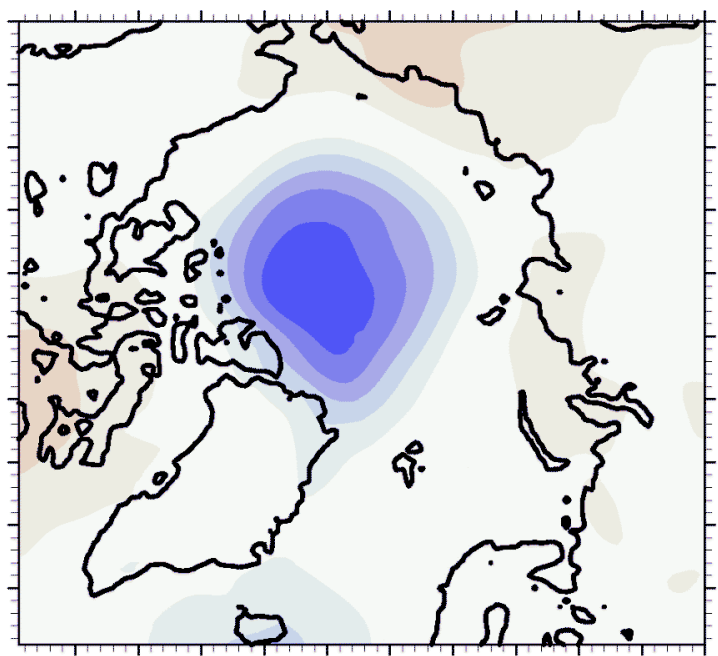

Model run, high-ice

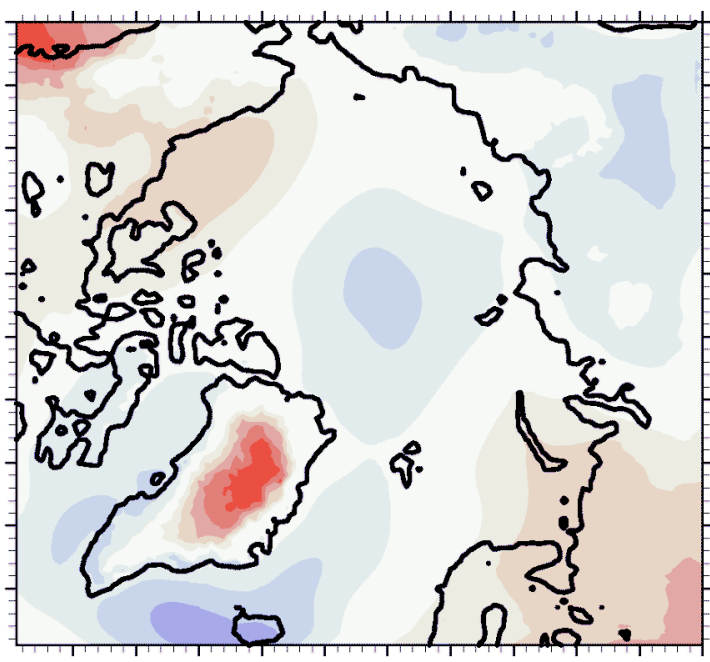

Model run, low-ice

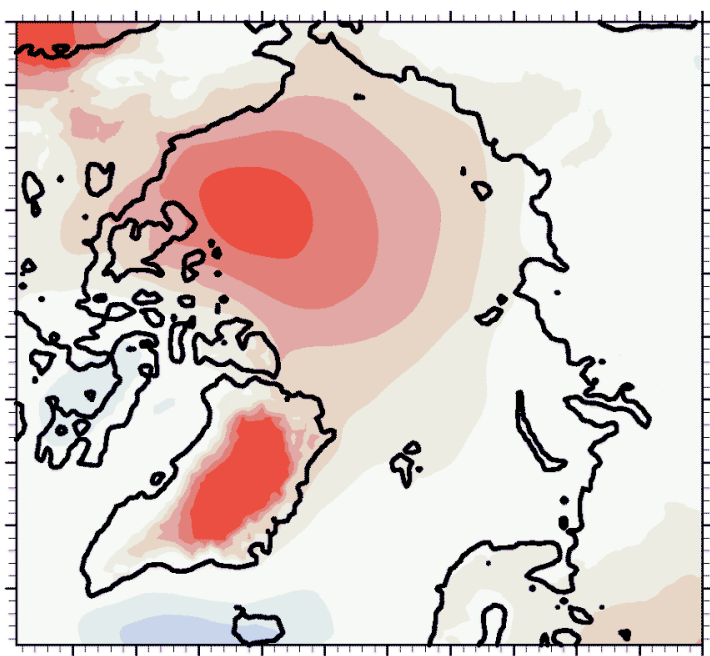

Model run, high - low

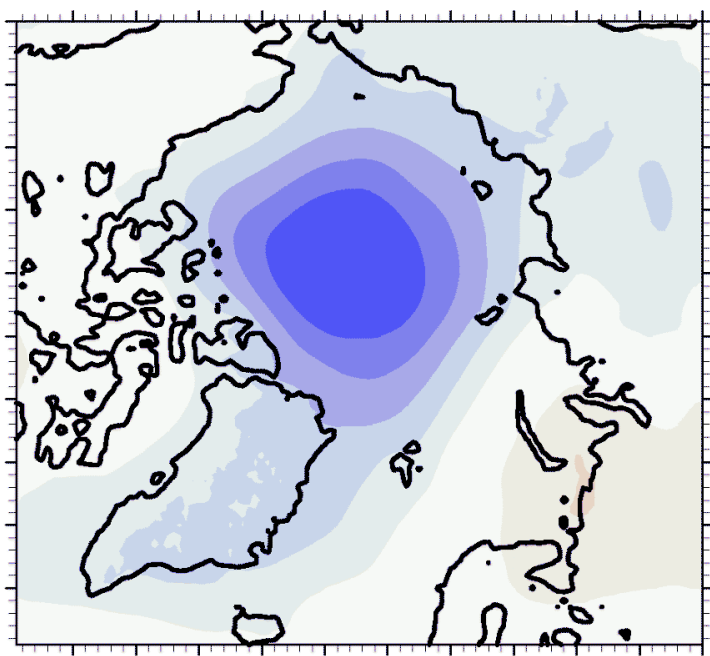

Fig. (6). Observed (left) and simulated (right) mean sea level pressure during summer (June to September) in "high-ice" years (top panel), "low-ice" years (middle panel), and difference between "high-ice" and "low-ice" years (bottom panel). "High-ice" and "low-ice" years are defined just as in Fig. (3). 


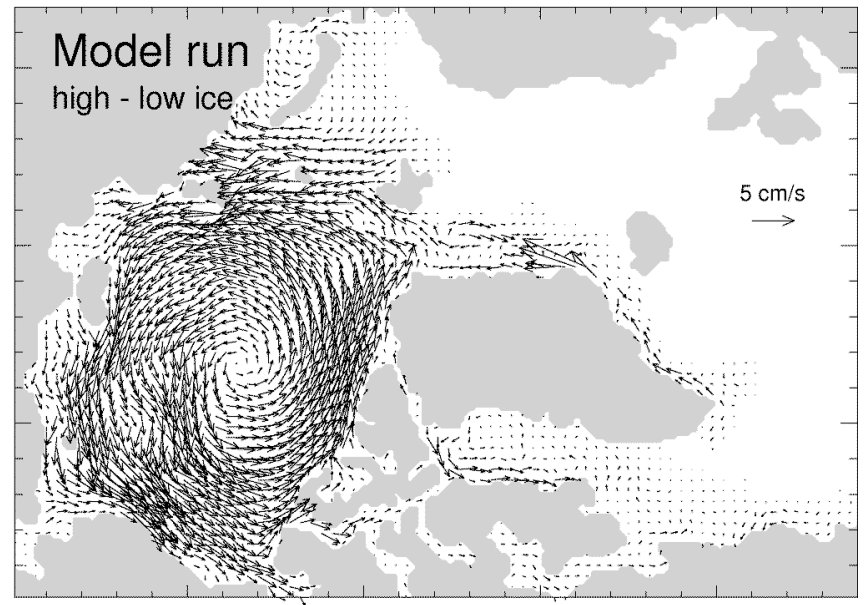

Fig. (7). Difference between "high-ice" and "low-ice" years of simulated mean sea-ice drift vectors during summer (June to September). For clarity reasons, only every third difference vector is displayed.

\section{SUMMARY AND DISCUSSION}

It has been shown that the variability of the Arctic summer sea-ice cover between 1988 and 2000 tends to concentrate beyond an area enclosed by an isopleth of barotropic planetary potential vorticity that marks the edge of the cyclonic rim current around the deep inner Arctic basin. Dynamic and thermodynamic arguments, which might explain the suppressed propagation of the variability signal farther into the inner Arctic, have been discussed along with variations of the atmospheric circulation as main driver for seaice variability. These dynamic and thermodynamic arguments lead to the conclusion that natural variability of the summer sea-ice cover is restricted to its peripheral zone and can enter the inner Arctic only to a minor degree as long as no substantial and permanent changes in the forcing push the Arctic climate system into another state. It is hypothesized that the interannual sea-ice variability may enter the inner Arctic basin primarily in case of a substantial warming of the upper Arctic Ocean, either due to a retreat of the cold halocline layer or due to a decrease of the exceptionally high summertime cloud cover in the central Arctic. At least up to the year 2001, a significant trend in summer cloud cover has not been observed [33].

As the sea-ice retreat in summer 2007 reached far into the Arctic basin and was exceptional in terms of the usual sea-ice variability, one might argue that the Arctic sea ice is no longer in a metastable state and has already passed a "tipping point" toward thinner and less extensive sea-ice cover [37]. Lindsay and Zhang (2005) [37] noted that internal thermodynamic changes related to the positive ice-albedo feedback, not external forcing, have dominated the icethinning process from 1988 to 2003, in particular subsequent to a strong decrease of thick multi-year ice during 1989-1990 when the AO was in an extreme high-index phase [22]. This finding agrees basically with the model results, which suggest that the thinning of the sea-ice cover in the early 1990 s is primarily a consequence of changes in the large-scale atmospheric circulation and not due to greenhouse gas induced warming of the Arctic. The latter might only have contrib- uted to maintain the trend afterwards, for instance by slowing the ice growth during winter.

The thinning of the sea-ice cover is a major reason for its increased response to variations in the atmospheric and oceanic circulations. However, the ice-thinning on its own does not represent a sufficient condition for the occurrence of extremely low sea-ice extent at the end of the summer, or even for its total disappearance. Model results by Dorn et al. (2007) [15] show that an Arctic climate state without summer sea ice is not stable under forcing conditions for the 1990s. A model simulation without sea ice at the end of the summer 1989 generates an ice thickness distribution and ice extent at the end of the 1990s which is quite similar to a corresponding simulation with very thick ice cover in 1989 [15]. Furthermore, recent model predictions of Arctic sea ice for the spring and summer of 2008 by Zhang et al. (2008) [38] show that another record low of summer sea ice can only be expected under similar atmospheric forcing conditions as in 2007. Forcing conditions as in the years from 2001 to 2006 will not result in further decline of the summer ice extent [38]. In summary, forcing conditions as in the recent past, except for 2007, are not sufficient for another record low of summer sea ice, in spite of the dramatic thinning of the ice cover in recent years.

Observational data show that the atmospheric circulation in summer 2007 was characterized by the typical, but exceptionally strong high pressure area over the Beaufort Sea [39]. In addition, exceptionally low pressure occurred over Siberia, which led to advection of warm air from the North Pacific region into the inner Arctic and favored a wind-forced ice drift toward Greenland and out of the Arctic through Fram Strait. It could be possible that the anomalous atmospheric circulation in summer 2007 was correlated with the growing La Niña event in the East Pacific, since there is some evidence from past events that La Niña induces atmospheric circulation patterns which favor low sea-ice extent in the Northern Hemisphere [40-42].

Furthermore, the anticyclonic atmospheric circulation in summer 2007 was accompanied by anomalously low cloudiness (approximately $20 \%$ below average) which led to a considerable increase in downwelling shortwave radiation [39]. This should have led to enhanced surface ice melt and is consistent with warmer sea surface temperatures, which in turn enhanced lateral and basal ice melt as discussed by Steele et al. (2008) [43] and Kay et al. (2008) [39]. Measurements by means of autonomous buoys indicate that the ocean-to-ice heat flux due to warming of the uppermost ocean layer played a significant role in the dramatic retreat of sea ice in the Beaufort Sea region during summer 2007 where extreme basal ice melt occurred [44].

Another process, which could have contributed to the increased vulnerability of the sea-ice cover, is the propagation of warm and salty intermediate Atlantic waters into the Arctic basin $[28,45]$. This condition might be associated with an increase in the upward oceanic heat flux through the halocline, which is certainly a small quantity compared to other heat fluxes, but earlier studies suggest that the ice cover is sensitive to small changes in oceanic heat flux $[46,47]$. A 
temperature increase in the intermediate Atlantic waters may involve such a small change and might thus have contributed to the thinning of the ice cover, since the inflow of anomalously warm and salty Atlantic waters at depth has already operated for some years. However, whether this process will continue in the future remains an open question.

The mechanisms causing atmospheric and oceanic variability on annual to decadal time scales are poorly understood to date. Model simulations by Maslowski et al. (2001) [48] suggest an oscillatory behavior of the Arctic Ocean system, driven by interannual variability of the atmosphere. Therefore, a temporal return to previous conditions or stabilization at the current level can not be excluded, when the atmospheric circulation promotes high-ice conditions for some years once again. At least further reduction in the summer sea-ice cover might take a longer time and occur at a lower rate than it has happened in previous years, when most of the ice reduction appeared over shallow shelf zones.

In principle, the recurrence of such anomalous conditions as in 2007 is possible and would reinforce the ice loss, maybe even induce abrupt reductions as seen in climate model simulations by Holland et al. (2006) [49]. However, the persistence of all these anomalies that appeared in 2007 is rather unlikely, since they are at least partly not a result of a continuous climate change of anthropogenic origin. It is more likely that the coincidence of several favorable factors for low sea-ice extent is responsible for this extreme event. Some of them are likely to persist or still strengthen in the near future and will preserve the vulnerability of the Arctic sea-ice cover to further decline, but the important role of internal climate variability in the recent decline and its unpredictability should be kept in mind when speculating about the time of possible disappearance of the Arctic summer seaice cover.

\section{ACKNOWLEDGEMENTS}

SSM/I sea-ice data were provided by the National Snow and Ice Data Center (NSIDC), Boulder, CO, and ERA-40 data by the European Centre for Medium-Range Weather Forecasts (ECMWF). Computational resources for carrying out the model simulations were provided by the North German Supercomputing Center (HLRN) within the project hbk00014. Finally, we thank Rüdiger Gerdes, Michael Karcher, Frank Kauker, and Elena Sokolova for their support, and we are deeply grateful to the two anonymous reviewers for many valuable suggestions.

\section{REFERENCES}

[1] Stroeve JC, Serreze MC, Fetterer F, et al. Tracking the Arctic's shrinking ice cover: Another extreme September minimum in 2004. Geophys Res Lett 2005; 32: L04501.

[2] Serreze MC, Holland MM, Stroeve J. Perspectives on the Arctic's shrinking sea-ice cover. Science 2007; 315: 1533-6.

[3] Stroeve J, Holland MM, Meier W, Scambos T, Serreze M. Arctic sea ice decline: Faster than forecast. Geophys Res Lett 2007; 34: L09501.

[4] Comiso JC, Parkinson CL, Gersten R, Stock L. Accelerated decline in the Arctic sea ice cover. Geophys Res Lett 2008; 35: L01703.

[5] Comiso JC. Arctic warming signals from satellite observations. Weather 2006; 61: 70-76.

[6] Stroeve J, Markus T, Meier WN, Miller J. Recent changes in the Arctic melt season. Ann Glaciol 2006; 44: 367-74.
Maslanik J, Drobot S, Fowler C, Emery W, Barry R. On the Arctic climate paradox and the continuing role of atmospheric circulation in affecting sea ice conditions. Geophys Res Lett 2007; 34: L03711.

[8] Corti S, Molteni F, Palmer TN. Signature of recent climate change in frequencies of natural atmospheric circulation regimes. Nature 1999; 398: 799-802.

[9] Eisenman I, Untersteiner N, Wettlaufer JS. On the reliability of simulated Arctic sea ice in global climate models. Geophys Res Lett 2007; 34: L10501.

[10] Comiso JC, Yang J, Honjo S, Krishfield RA. Detection of change in the Arctic using satellite and in situ data. J Geophys Res 2003; 108: 3384 .

[11] Ogi M, Wallace JM. Summer minimum Arctic sea ice extent and the associated summer atmospheric circulation. Geophys Res Lett 2007; 34: L12705.

[12] Vavrus SJ. The response of the coupled Arctic sea ice - atmosphere system to orbital forcing and ice motion at $6 \mathrm{kyr}$ and $115 \mathrm{kyr}$ BP. J Clim 1999; 12: 873-96.

[13] Dethloff K, Rinke A, Benkel A, et al. A dynamical link between the Arctic and the global climate system. Geophys Res Lett 2006; 33: L03703.

[14] Sokolova E, Dethloff K, Rinke A, Benkel A. Planetary and synoptic scale adjustment of the Arctic atmosphere to sea ice cover changes. Geophys Res Lett 2007; 34: L17816.

[15] Dorn W, Dethloff K, Rinke A, et al. Sensitivities and uncertainties in a coupled regional atmosphere-ocean-ice model with respect to the simulation of Arctic sea ice. J Geophys Res 2007; 112: D10118.

[16] Cavalieri D, Gloerson P, Zwally J. DMSP SSM/I monthly polar gridded sea ice concentrations, 1988 to 2003; 1990, updated 2004 Digital media. edited by J. Maslanik and J. Stroeve, National Snow and Ice Data Center, Boulder, CO

[17] Robock A. Introduction: Mount Pinatubo as a test of climate feedback mechanisms. In: Robock A, Oppenheimer C, editors. Volcanism and the Earth's Atmosphere. vol. 139 of Geophysical Monograph. AGU, Washington DC; 2003. p. 1-8.

[18] Hilmer M, Lemke P. On the decrease of Arctic sea ice volume Geophys Res Lett 2000; 27: 3751-4.

[19] Wang J, Ikeda M, Zhang S, Gerdes R. Linking the northern hemisphere sea-ice reduction trend and the quasi-decadal arctic sea-ice oscillation. Clim Dyn 2005; 24: 115-30.

[20] Deser C, Walsh JE, Timlin MS. Arctic sea ice variability in the context of recent atmospheric circulation trends. J Clim 2000; 13: 617-33.

[21] Björk G, Söderkvist J. Dependence of the Arctic Ocean ice thickness distribution on the poleward energy flux in the atmosphere. J Geophys Res 2002; 107: 3173.

[22] Rigor IG, Wallace JM. Variations in the age of Arctic sea-ice and summer sea-ice extent. Geophys Res Lett 2004; 31: L09401.

[23] Juckes MN, McIntyre ME. A high-resolution one-layer model of breaking planetary waves in the stratosphere. Nature $1987 ; 328$ : 590-6.

[24] Karcher M, Kauker F, Gerdes R, Hunke E, Zhang J. On the dynamics of Atlantic Water circulation in the Arctic Ocean. J Geophys Res 2007; 112: C04S02.

[25] Holloway G, Dupont F, Golubeva E, et al. Water properties and circulation in Arctic Ocean models. J Geophys Res 2007; 112: C04S03.

[26] Yang J. The Arctic and subarctic ocean flux of potential vorticity and the Arctic Ocean circulation. J Phys Oceanogr 2005; 35: 2387 2407.

[27] Schauer U, Fahrbach E, Osterhus S, Rohardt G. Arctic warming through the Fram Strait: Oceanic heat transport from 3 years of measurements. J Geophys Res 2004; 109: C06026.

[28] Polyakov IV, Beszczynska A, Carmack EC, et al. One more step toward a warmer Arctic. Geophys Res Lett 2005; 32: L17605.

[29] Steele M, Boyd T. Retreat of the cold halocline layer in the Arctic Ocean. J Geophys Res 1998; 103: 10419-35.

[30] Boyd TJ, Steele M, Muench RD, Gunn JT. Partial recovery of the Arctic Ocean halocline. Geophys Res Lett 2002; 29: 1657.

[31] Maykut GA, Perovich DK. The role of shortwave radiation in the summer decay of a sea ice cover. J Geophys Res 1987; 92: 7032 44.

[32] Schweiger AJ, Lindsay RW, Key JR, Francis JA. Arctic clouds in multiyear satellite data sets. Geophys Res Lett 1999; 26: 1845-8. 
[33] Schweiger AJ. Changes in seasonal cloud cover over the Arctic seas from satellite and surface observations. Geophys Res Lett 2004; 31: L12207.

[34] Rigor IG, Wallace JM, Colony RL. Response of sea ice to the Arctic Oscillation. J Clim 2002; 15: 2648-63.

[35] Serreze MC, Maslanik JA, Scambos TA, et al. A record minimum arctic sea ice extent and area in 2002. Geophys Res Lett 2003; 30: 1110 .

[36] Proshutinsky AY, Johnson MA. Two circulation regimes of the wind-driven Arctic Ocean. J Geophys Res 1997; 102: 12493-514.

[37] Lindsay RW, Zhang J. The thinning of Arctic sea ice, 1988-2003: Have we passed a tipping point? J Clim 2005; 18: 4879-94.

[38] Zhang J, Steele M, Lindsay R, Schweiger A, Morison J. Ensemble 1 -Year predictions of Arctic sea ice for the spring and summer of 2008. Geophys Res Lett 2008; 35: L08502.

[39] Kay JE, L'Ecuyer T, Gettelman A, Stephens G, O'Dell C. The contribution of cloud and radiation anomalies to the 2007 Arctic sea ice extent minimum. Geophys Res Lett. 35; 2008: L08503.

[40] Pozo-Vázquez D, Esteban-Parra MJ, Rodrigo FS, Castro-Díez Y. The association between ENSO and winter atmospheric circulation and temperature in the North Atlantic region. J Clim 2001; 14: 3408-20.

[41] Liu J, Curry JA, Hu Y. Recent Arctic Sea Ice Variability: Connections to the Arctic Oscillation and the ENSO. Geophys Res Lett 2004; 31: L09211.
[42] Ukita J, Honda M, Nakamura H, et al. Northern Hemisphere sea ice variability: lag structure and its implications. Tellus 2007; 59A: 261-72.

[43] Steele M, Ermold W, Zhang J. Arctic Ocean surface warming trends over the past 100 years. Geophys Res Lett 2008; 35: L02614.

[44] Perovich DK, Richter-Menge JA, Elder BC, Claffey KJ. Arctic sea ice melt in summer 2007: Surface and bottom ice ablation. Eos Trans AGU 2007; 88(52). Fall Meet. Suppl., Abstract C21C-07.

[45] Walczowski W, Piechura J. New evidence of warming propagating toward the Arctic Ocean. Geophys Res Lett 2006; 33: L12601.

[46] Maykut GA, Untersteiner N. Some results from a time-dependent thermodynamic model of sea ice. J Geophys Res 1971; 76: 155075 .

[47] McPhee MG, Kikuchi T, Morison JH, Stanton TP. Ocean-to-ice heat flux at the North Pole environmental observatory. Geophys Res Lett 2003; 30: 2274

[48] Maslowski W, Marble DC, Walczowski W, Semtner AJ. On largescale shifts in the Arctic Ocean and sea-ice conditions during 1979. 98. Ann Glaciol 2001; 33: 545-50.

[49] Holland MM, Bitz CM, Tremblay B. Future abrupt reductions in the summer Arctic sea ice. Geophys Res Lett 2006; 33: L23503.

(C) Dorn et al.; Licensee Bentham Open.

This is an open access article distributed under the terms of the Creative Commons Attribution License (http://creativecommons.org/licenses/by/2.5/), which permits unrestrictive use, distribution, and reproduction in any medium, provided the original work is properly cited. 